\section{Verrucous lichen planus: a rare presentation of a common condition}

\author{
Moutusi Audhya, Jenny S. Varughese, \\ Yuti C. Nakhwa \\ Department of Dermatology, \\ Venereology and Leprosy, Mahatma \\ Gandhi Medical College and Research \\ Institute, Pondicherry, India
}

\section{Abstract}

Lichen planus is a chronic papulosquamous dermatoses in which both skin and mucosae are involved. There are various morphological forms of lichen planus. Hypertrophic lichen planus is one of the rare clinical variants. Herein, we report a very unusual presentation of hypertrophic lichen planus. A similar presentation has not been reported in literature yet, to the best of our knowledge.

\section{Introduction}

The dermatosis, lichen planus was first described by Erasmus Wilson in 1869 and is characterized by purple, polygonal, pruritic, papular eruption of unknown etiology affecting the skin and can also involve the mucous membranes and the nails. ${ }^{1}$ Lichen refers to the dry and undulating lichen-like appearance affecting skin. It is associated with oxidative stress, certain medications and diseases, however the underlying pathology is not exactly known. ${ }^{2}$

Lichen planus may be divided morphologi- cally into the following types: annular lichen planus, linear lichen planus, hypertrophic lichen planus, atrophic lichen planus, vesiculobullous lichen planus, ulcerative lichen planus, follicular lichen planus, actinic lichen planus and lichen planus pigmentosus. ${ }^{3}$ According to the site of involvement there is lichen planus of the palms and soles (palmoplantar lichen planus), mucosal lichen planus, lichen planus of the nails, lichen planus of the scalp (leading to cicatricial alopecia), inverse lichen planus. ${ }^{3}$ Hypertrophic lichen planus/verrucosa is one of the relatively rare clinical variants. It occurs as a thick, elevated, purplish hypertrophic lesion seen mainly over the extremities, shin and interphalangeal joints. The development of hypertrophic lesions greatly lengthens the course of the disease. ${ }^{4}$ Here we present the report of an elderly female who came with a very unusual presentation of hypertrophic lichen planus.

\section{Case Report}

A 70-year-old woman presented to the outpatient department with multiple raised, warty lesions over lower legs and dorsa of feet bilaterally for the last 1 year (Figure 1a). The lesions were extremely pruritic. They initially started as small papules and gradually increased to attain the present size. She had received treatment previously in the form of certain topical ointments without any relief.

On examination, she was found to have multiple well defined hyperpigmented verrucous plaques with follicular prominence, of varying sizes seen bilaterally over the lower legs and the dorsa of feet (Figure 1b,c). She had no nail changes and the scalp and mucosae were normal. There was no evidence of koebnerization and wickham's striae were not apparently visi-
Correspondence: Moutusi Audhya, Department of Dermatology, Venereology and Leprosy, Mahatma Gandhi Medical College and Research Institute, Pondicherry 607402, Kirumampakkam, Cuddalore, TN, India.

Tel. +91.0413.2615449 - Fax: +91.0413.2615457.

E-mail: drmoutusiaudhya@gmail.com

Key words: verrucous, lichen planus, hypertrophic.

Contributions: the authors contributed equally.

Conflict of interests: the authors declare no potential conflict of interests.

Received for publication: 8 October 2013.

Revision received: 18 January 2014.

Accepted for publication: 25 Jnuary 2014.

This work is licensed under a Creative Commons Attribution NonCommercial 3.0 License (CC BYNC 3.0).

(C) Copyright M. Audhya et al., 2014

Licensee PAGEPress, Italy

Dermatology Reports 2014; 6:5113

doi:10.4081/dr.2014.5113

ble. Based on these findings a provisional clinical diagnosis of hypertrophic lichen planus was made.

Systemic examination did not reveal any abnormality. Routine hematological and biochemical investigations were normal.

A histopathological examination revealed basket weave type of hyperkeratotic, acanthotic squamous epithelium with elongation of the rete ridges. The sub epithelium showed pigment incontinence and dense bands of lymphohistocytic infiltration in papillary dermis hugging the epidermis (Figure 2). Based on the above findings a definite diagnosis of hypertrophic lichen planus was made.

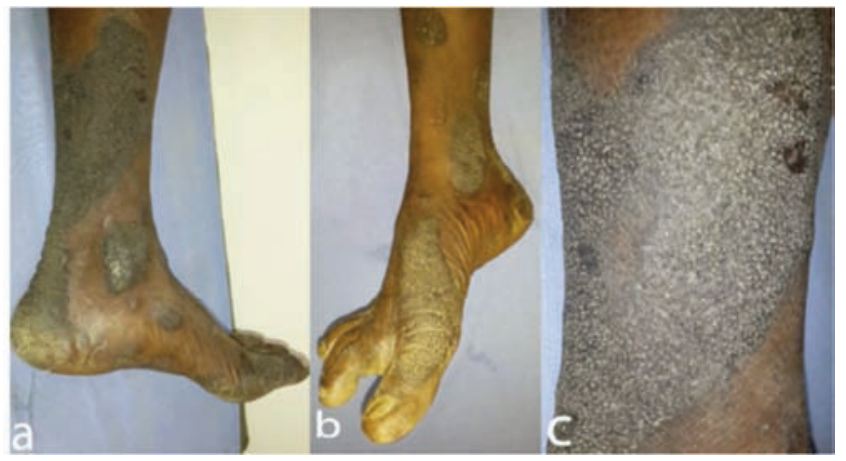

Figure 1. a) Hyperpigmented verrucous follicular pitted plaque over the shin; b) dorsa of the feet; c) a clear view of the pits present over the verrucous plaque.

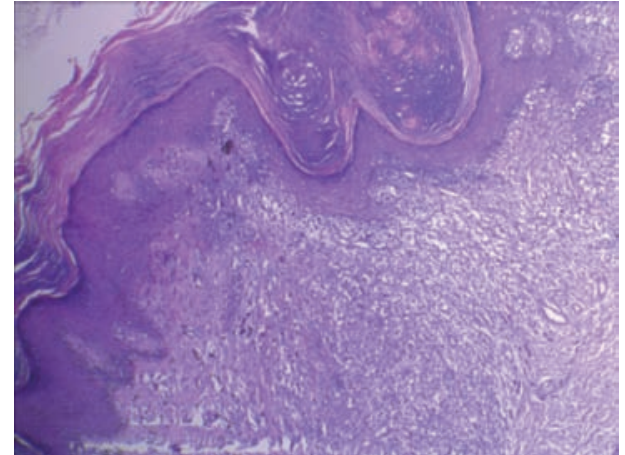

Figure 2. Photomicrograph showing hyperkeratosis, papillomatosis, hypergranulosis with elongation of rete ridges and lymphocytic infiltration in the dermis (Hematoxylin \& Eosin, $\times 40$ ) 


\section{Discussion}

Lichen planus (Greek tree moss, Latin planus flat) is a common inflammatory papulosquamous disorder that affects the skin, mucous membranes, nails and hair.

The prevalence of disease is $1 \%$ of the general population. ${ }^{5}$ Hypertrophic lichen planus (lichen planus hypertrophicus) occurs on the extremities especially the shins. It is the most pruritic variant of all lichen planus. Lesions are thick, elevated, purplish in colour and hyperkeratotic. The variant heals with scar, hypopigmentation or hyperpigmentation. ${ }^{4}$ There are reports of metastatic squamous cell carcinoma and keratoacanthoma arising from long standing hypertrophic lesions of lichen planus. ${ }^{6,7}$ The morphology can be very varied ranging from hyperkeratotic papules to extremely thick plaque type of lesions.

The histopathological appearance of hypertrophic lichen planus shows acanthosis, papillomatosis, hypergranulosis and hyperkeratosis, ${ }^{8}$ which correlated with the histopathological picture in our patient. Hypertrophic lichen planus is a rare presentation, having a varying clinical picture which may pose a difficulty in diagnosis. ${ }^{6}$

\section{Conclusions}

Hypertrophic lichen planus is one of the less commonly encountered variants of lichen planus. The resistance to treatment is a striking feature in this condition. Though it has been mentioned in literature that the lesions in hypertrophic lichen planus can be extremely hyperkeratotic, ${ }^{4}$ however in our patient the morphology of the lesions was very unusual. The patient was started on treatment with topical high potent steroid under occlussion and was planned for intralesional steroid therapy. However she was lost to follow up and did not report back to us. We report the patient for the unusual presentation of a relatively common condition.

\section{References}

1. Kanwar AJ, De D. Lichen planus in children. Indian J Dermatol Venereol Leprol 2010;76:366-72

2. Symcat. Lichen planus. What you need to know. Available from: http://www. symcat.com/conditions/lichen-planus.
Accessed on: January 2014

3. Usatine RP, Tinitigan M. Diagnosis and treatment of lichen planus. Am Fam Physician 2011;84:53-60.

4. Breathnach SM, Black MM. Lichen planus and lichenoid disorders. In: Burns T, Breathnach S, Cox N, Griffiths C, eds. Rook's text book of dermatology. 8th ed. 0xford: Blackwell Science; 2010. pp 10-42.

5. Sripathi H, Kudur MH, Prabhu S, Pai SB. Punctate keratotic papules and plaques over palm. Diagnosis: hypertrophic lichen planus of palm. Indian $\mathrm{J}$ Dermatol Venereol Leprol 2010;76:449.

6. Sharma VK, Achar A, Ramam M, Singh MK. Multiple cutaneous horns overlying lichen planus hypertrophicus. $\mathrm{Br} \mathrm{J}$ Dermatol 2001;144:424-5.

7. Fried TK, Flaig MJ, Ruzicka T, Rupec RA [Verrucous squamous cell carcinoma complicating hypertrophic lichen planus. Three case reports and review of the literature]. Hautarzt 2011;62:40-5. [Article in German].

8. Garg VK, Nangia A, Logani K, Sharma RC. Lichen planus: a clinico-histopathological. Indian J Dermatol Venereol Leprol 2000; 66:193. 